\title{
Recent Advances in Immunotherapy in Metastatic NSCLC
}

\author{
Pranshu Bansal1,2, Diaa Osman ${ }^{1,2}$, Gregory N. Gan ${ }^{1,3}$, George R. Simon ${ }^{4}$ and \\ Yanis Boumber $1,5 *+$
}

'Department of Internal Medicine, Division of Hematology/Oncology, University of New Mexico Comprehensive Cancer Center, University of New Mexico School of Medicine, Albuquerque, NM, USA, ${ }^{2}$ Hematology/Oncology Fellowship Program, University of New Mexico Comprehensive Cancer Center, University of New Mexico School of Medicine, Albuquerque, NM, USA, ${ }^{3}$ Section of Radiation Oncology, University of New Mexico Comprehensive Cancer Center, Albuquerque, NM, USA, ${ }^{4}$ Department of Thoracic and Head/Neck Medical Oncology, Division of Cancer Medicine, University of Texas MD Anderson Cancer Center, Houston, TX, USA, ${ }^{5}$ Molecular Therapeutics Program, Department of Hematology/Oncology, Fox Chase Cancer Center, Philadelphia, PA, USA

\section{OPEN ACCESS}

Edited by:

Barbara Jennifer Gitlitz, Keck School of Medicine of USC,

USA

Reviewed by:

Vera Hirsh,

McGill University, Canada K. Shilo,

Ohio State University, USA

*Correspondence: Yanis Boumber

Yanis.Boumber@fccc.edu

tPresent address: Yanis Boumber,

Department of Hematology/ Oncology, Fox Chase Cancer Center,

Philadelphia, PA, USA

Specialty section:

This article was submitted to Thoracic Oncology,

a section of the journal

Frontiers in Oncology

Received: 17 July 2016 Accepted: 26 October 2016 Published: 14 November 2016

Citation:

Bansal P, Osman D, Gan GN, Simon GR and Boumber Y (2016) Recent Advances in Immunotherapy in Metastatic NSCLC.

Front. Oncol. 6:239. doi: 10.3389/fonc.2016.00239
Non-small cell lung cancer (NSCLC) is one of most common malignancies and the leading cause of cancer deaths worldwide. Despite advances in targeted therapies, majority of NSCLC patients do not have targetable genomic alterations. Nevertheless, recent discovery that NSCLC is an immunogenic tumor type, and several breakthroughs in immunotherapies have led to rapid expansion of this new treatment modality in NSCLC with recent FDA approvals of programed death receptor- 1 inhibitors, such as nivolumab and pembrolizumab. Here, we review promising immunotherapeutic approaches in metastatic NSCLC, including checkpoint inhibitors, agents with other mechanisms of action, and immunotherapy combinations with other drugs. With advent of immunotherapy, therapeutic options in metastatic NSCLC are rapidly expanding with the hope to further expand life expectancy in metastatic lung cancer.

Keywords: PDL1, PD1, CTLA4, NSCLC, cancer immunotherapy

\section{IMMUNOTHERAPY IN CANCER: INTRODUCTION}

In 1957, Sir Macfarlane Burnet and Lewis Thomas first recognized the antigenicity of tumors and discovered immune surveillance in tumorigenesis (1). However, translation of the use of immune system for clinically meaningful benefits has started to realize only recently.

Compared to the circulating tumor antigen-specific T-cells, T-cells in the tumor microenvironment have impaired effector functions (2-4). Mice infected with chronic lymphocytic choriomeningitis virus (LCMV) show upregulation of negative costimulatory receptors on T-cells, including cytotoxic T-lymphocyte antigen 4 (CTLA-4), programed death receptor-1 (PD-1), T-cell immunoglobulin domain and mucin domain-3 (TIM-3), lymphocyte activation gene-3 protein (LAG-3), and others (5). The loss of T-cells effector function during chronic infections is similar in cancer where T-cells chronically exposed to tumor antigens enter a state of exhaustion (6). Major efforts concentrating on reversing T-cell exhaustion by inhibiting negative checkpoints with antibodies against PD-1 and its ligand, programed death receptor-1 ligand (PD-L1) are at the forefront of immunotherapy research.

Clinical success with immunotherapy was first seen in highly immunogenic malignant melanoma. High-dose interleukin-2 (IL-2) showed an objective response rate (ORR) of 16\% (7). Interestingly, many complete responders experience long-term responses, and IL-2 was used extensively in melanoma patients despite high toxicities (8). This changed with approvals of CTLA-4 inhibitor ipilimumab in 2011, and PD-1 inhibitors, such as pembrolizumab and nivolumab, in 2014, which 
have better side effect profiles. The response rates with ipilimumab are $\sim 10 \%$, while PD- 1 inhibitors have $40 \%$ ORR $(8,9)$. Combination studies of ipilimumab and nivolumab have shown ORR of $42-60 \%(9,10)$, unprecedented in melanoma, have led to survival benefits and safer treatment options.

Lung cancer has been viewed as non-immunogenic tumor where immunotherapies, such as BCG and IL-2, showed no efficacy $(11,12)$. However, with recent success of immune checkpoint inhibitors, this has changed, and here we review the recent data in non-small cell lung cancer (NSCLC) and emerging immunotherapies.

\section{ESTABLISHED SINGLE-AGENT CHECKPOINT INHIBITORS}

\section{Nivolumab}

Nivolumab is a fully human IgG4 antibody against PD-1, which can activate host immune system. In phase I studies in pretreated NSCLC patients, nivolumab showed ORR of $17-18 \%(13,14)$. A phase III trial in patients with advanced squamous NSCLC compared nivolumab with docetaxel, demonstrating median OS 9.2 vs. 6.2 months (15). In another phase III trial, patients with advanced non-squamous NSCLC progressing on platinumdoublet chemotherapy were randomized to receive nivolumab or docetaxel, showing median OS 12.2 months with nivolumab and 9.4 months with docetaxel (16). The subgroup of patients without numerical progression-free survival (PFS) advantage with nivolumab included never smokers, patients with KRAS wild type, EGFR-mutant tumors, although this study was not powered for subgroup analysis. PD-L1 expression was detected by IHC using a human PDL-1 antibody (Epitomics). Cutoffs were divided into three groups: 1, 5, and 10\%. Quantifiable PDL-1 expression was seen in $78 \%$ patients. OS difference favoring nivolumab was found to be significant across all subgroups. No meaningful advantage in survival was seen in patients with PDL1-negative tumors (16). FDA approved nivolumab for NSCLC patients progressing on platinum-doublet chemotherapy in 2015.

The role of nivolumab in patients with Eastern Cooperative Oncology Group performance status 2, as maintenance therapy, and in combination with other therapies remains to be established. A five-arm, phase II basket study has been launched with $\sim 2000$ NSCLC patients including PS2 patients, maintenance cohorts, and epidermal growth factor receptor positive (EGFR+)/ anaplasplastic lymphoma kinase positive (ALK+) patients treated with erlotinib or crizotinib with and without nivolumab (CHECKMATE 370; NCT02574078).

\section{Pembrolizumab}

Pembrolizumab is another monoclonal antibody targeting PD-1. A randomized phase II/III study compared pembrolizumab with docetaxel in advanced NSCLC patients (70\% non-squamous, $22 \%$ squamous histology), excluding those with PD-L1-negative tumors and stratifying by PDL-1 expression 1-49\% ( $57 \%$ patients) and $>50 \%(\sim 43 \%)$. The ORR with pembrolizumab was $\sim 18$ vs. $9 \%$ with docetaxel, similar to nivolumab studies. The ORR in patients with $>50 \%$ PD-L1 expression was higher: $~ 30$ vs. $8 \%$ with docetaxel. Median OS was 14.9 months for the pembrolizumab $2 \mathrm{mg} / \mathrm{kg}, 17.3$ months for the pembrolizumab $10 \mathrm{mg} / \mathrm{kg}$, and 8.2 months for the docetaxel group (17). FDA approved pembrolizumab in 2015 for patients with PDL1 + NSCLC patients with mandatory immunohistochemistry PD-L1 diagnostic test 22C3 (Dako).

\section{Atezolizumab}

Programed death receptor-1 has two ligands: PD-L1 (B7-H1) and PD-L2 (B7-DC) $(18,19)$. PD-L1 is expressed on hematopoietic, endothelial, and epithelial cells (20). Atezolizumab is an IgG1 antibody to PD-L1. In a phase II study (POPLAR) of NSCLC patients progressing on platinum-based chemotherapy, atezolizumab was compared with docetaxel. The median OS for atezolizumab was significantly better than with docetaxel (12.6 vs. 9.7 months, $p=0.04$ ). The improvement correlated with PD-L1 expression on both tumor and tumor-infiltrating immune cells. Although the ORR was $15 \%$ for both arms, subgroup of patients with high PD-L1 expressing tumors had ORR of $38 \%$ with atezolizumab and $13 \%$ with docetaxel (21). In another large single-arm phase II study (BIRCH), PD-L1+ patients included treatment-naïve NSCLC patients in cohort 1 ; cohorts $2 / 3$ included patients after 1-2 lines of chemotherapy. The ORR was $19 \%$ in cohort $1,17 \%$ in cohorts $2 / 3$. PD-L1 positivity was defined as $>5 \%$ tumor cells positive or $>5 \%$ tumor area with immune cells staining positive (22). FDA has granted priority review for atezolizumab, and final decision approval is expected on October 2016.

\section{Durvalumab}

Similar to atezolizumab, durvalumab is an IgG1 antibody to PD-L1. In a phase I study, durvalumab was administered to patients with NSCLC progressing after chemotherapy. Among 149 patients, ORR was $14 \%$ favoring PD-L1+ patients (ORR $23 \%$ ) and squamous (ORR 21\%) compared to non-squamous histology (ORR 10\%) (23). In treatment-naive patients with advanced NSCLC, ORR was $25 \%$ in a recent phase I/II study (24). ATLANTIC is an ongoing phase II study with durvalumab in NSCLC patients progressing after at least two prior chemotherapies (NCT02087423).

\section{Avelumab}

Similar to durvalumab, avelumab is a fully human IgG1 antibody against PDL1. In a phase Ib study, 184 NSCLC patients progressing on platinum-based chemotherapy, avelumab showed an ORR of $12 \%$ ( $14 \%$ in PD-L1 + population) (25). JAVELIN lung 100 is an ongoing phase III trial evaluating avelumab vs. platinumbased doublet chemotherapy in treatment-naïve NSCLC patients (NCT02576574). JAVELIN lung 200 is a phase III trial in patients progressing after platinum-based chemotherapy, comparing avelumab to docetaxel (NCT02395172).

\section{PD-1, PD-L1 Targeting Agents: Selecting the Right Patient Population}

Scagliotti et al. first demonstrated difference in survival in NSCLC patients treated with platinum-doublet chemotherapy based on histology, a biomarker of chemotherapy response. Squamous 
histology patients did better with cisplatin/gemcitabine, while adenocarcinoma patients had improved OS on cisplatin/pemetrexed combination (26).

Predicting responses to immunotherapy is more complicated; PD-L1 expression is one potential marker. PD-L1 expression can change over time. PD-L1 expression at initial tumor biopsy does not always correlate with antitumor activity (27). Thommen et al. evaluated expression of checkpoints on CD8+ T-cells from patients with advanced NSCLC and developed a cumulative inhibitory score based on sum expression of several receptors. Significant increase in the score was seen in patients with node positive, advanced stage, while tumor size did not affect it. An inverse correlation between PDL-1 expression and effector function of CD8+ T-cells treated with PD-1 antibody was observed (28). While PD-L1 expression is one of the markers for response in NSCLC, prior smoking and high mutational load correlate with responsiveness, suggesting that better predictive biomarkers or scores are needed (29). Schumacher et al. developed cancer immunogram with seven different immune parameters including mutational load to help predict responsiveness of tumors to checkpoint inhibitors (30). Efforts should be focused in this direction to help identifying the target population and to drive down treatment costs.

\section{Ipilimumab and Tremelimumab}

Ipilimumab and tremelimumab are recombinant monoclonal antibodies against cytotoxic CTLA-4 that block CTLA-4 interaction with its ligands, such as CD80 and CD86. This blockade augments T-cell activation and proliferation, leading to tumor infiltration by T-cells and tumor regression (31). Although response rates with single-agent CTLA-4 inhibitor in NSCLC have been disappointing, there is considerable interest in exploiting this pathway in combination with other checkpoint inhibitors (32). In a phase II study, ipilimumab in combination with chemotherapy showed modest improvement in PFS in patients with advanced NSCLC (33). The benefit was limited to patients who received phased ipilimumab, allowing exposure to chemotherapy before ipilimumab (33). Encouraging results seen in early stage combination trials of CTLA-4 with PD-1 and PD-L1 inhibitors are discussed below.

\section{Epigenetic Approaches to Improve Immunotherapy Responses}

Epigenetic silencing and loss of gene expression is a hallmark of cancer (34). DNA-demethylating and histone-deacetylating agents show modest benefit in solid tumors $(35,36)$. Some patients may have durable response to subsequent chemotherapy or immunotherapy after receiving epigenetic modulators (37). Epigenetic therapy could sensitize tumors to subsequent therapy by altering tumor genomics, increasing tumor antigenicity (35, $38,39)$. In a phase I/II trial, heavily pretreated NSCLC patients received AZA and etinostat. Among 65 patients treated in phase II portion, 2 responded (37). Six patients from this trial subsequently received PD-1 inhibitors and five of the six patients showed $\mathrm{PR}$, including three patients with durable responses for 14-26 months (40).
Strong preclinical rationales for the combining epigenetic drugs with immunotherapy remains, including induction of IRF-7 gene, secretion of INF-alpha, synergy between AZA and CTLA4, and others $(38,40)$. Ongoing studies are evaluating potential combination of demethylating agents and HDAC inhibitors with nivolumab, pembrolizumab, and durvalumab, including patients failing prior PD-1/PDL-1 therapy (NCT01928576, NCT02638090, NCT02437176, NCT02437136, NCT02805660).

\section{EMERGING SINGLE-AGENT CHECKPOINT INHIBITORS}

\section{T-Cell Immunoglobulin and Mucin Domain-3-Containing Molecule 3}

With the success of PD-1/PDL- 1 and CTLA- 4 inhibitors in NSCLC, there is an increase interest in exploring other immune checkpoint regulators and understanding mechanisms of resistance to checkpoint inhibitors. Ectopic expression of TIM-3 was previously reported as an independent negative prognostic factor in NSCLC (2). Upregulation of alternative immune checkpoints, notably TIM-3, is implicated in PD-1 inhibitors resistance (39). Hammerman et al. showed upregulation of TIM-3 in PD-1 antibody-bound T-cells and a survival advantage in mice lung adenocarcinoma xenografts with addition of TIM-3 antibody to PD-1 inhibitor. They found similar upregulation of TIM-3 in biopsies from patients progressing on PD-1 therapy (41). Currently, the first in humans phase I-Ib/II trial is ongoing with MBG453 antibody against TIM-3 in combination with PDR001 PD-1 inhibitor (NCT02608268) in patients with advanced solid malignancies, including NSCLC.

\section{Lymphocyte Activation Gene-3}

Lymphocyte activation gene- 3 is a transmembrane protein, closely related to CD4 that binds major histocompatibility complex II (42). LAG-3 is co-negative regulator of effector T cells (43). Regulatory T-cells (Tregs) express LAG-3 that is upregulated in the presence of effector T-cells, leading to decreased antitumor immunity (44). LAG-3 antibodies inhibit Tregs (44). Preclinical data in multiple tumors demonstrated prolonged survival with dual PD-1/LAG-3 inhibition (45). Tissue samples from patients with ovarian epithelial cancers tumor-derived T-lymphocytes showed enrichment for coexpression of LAG-3 and PD-1 (46). Most of LAG-3 data at this time remain preclinical, and efficacy in solid malignancies remains to be seen. Urelumab (BMS-986016) and LAG525 are anti-LAG-3 antibodies investigated in early phase clinical trials in solid tumors including NSCLC alone and in combination with nivolumab or PDR-001 (NCT02658981, NCT01968109, NCT02460224).

\section{EMERGING SINGLE-AGENT IMMUNOMODULATING DRUGS}

\section{Bavituximab}

Bavituximab is a chimeric immunoglobulin antibody targeting a common phospholipid, phosphatidyl serine (PS), on tumor 
vascular endothelium (47). In normal cells, PS is expressed on internal membrane surface; however, in tumors, it becomes exposed on endothelial cells. Bavituximab binds to PS in a $\beta 2$-glycoprotein I-dependent manner leading to antitumor effects such as antibody-dependent cell-mediated toxicity. Bavituximab prevents interaction between PS on apoptotic tumor cells and macrophages and decreases secretion of antiinflammatory immunosuppressive molecules, such as TGF- $\beta$ and IL-10 $(48,49)$.

In a phase II trial, docetaxel + bavituximab $(\mathrm{D}+\mathrm{B})$ was compared to docetaxel + placebo $(\mathrm{D}+\mathrm{P})$ in patients with locally advanced lung adenocarcinoma. The $\mathrm{D}+\mathrm{B}$ combination was well tolerated, and results were encouraging with an improvement of ORR from $11.3 \%(\mathrm{D}+\mathrm{P}$ arm) to $17.1 \%(\mathrm{D}+\mathrm{B})(50)$. The confirmatory phase III SUNRISE trial was halted when at $33 \%$ events it failed to show OS advantage of docetaxel + bavituximab combination (NCT01999673). A combination immunotherapy trial with durvalumab (PD-L1 inhibitor) and bavituximab in recurrent NSCLC is ongoing (NCT02673814).

\section{Indoleamine 2,3-Deoxygenase}

Indoleamine 2,3-deoxygenase (IDO) is a cytoplasmic tryptophan catabolic enzyme that plays a significant role in T-cell suppression (51). High levels of IDO were first reported in human placenta (52). Inhibition of IDO in mice placenta leads to T-cell-mediated rejection of allogeneic conceptii (53). In addition to promoting immune tolerance to fetus in placenta, IDO-mediated depletion of tryptophan prevents excessive T-cell activation and lung inflammation (54). IDO supports development of immune tolerance to tumor antigens, activation of regulatory T-cells, and inhibition of cytotoxic T-cells and NK cells and is a relevant target in tumor immunology (55).

An ongoing trial is evaluating a combination of IDO inhibitor indoximod with docetaxel and Tergenpumatucel-L in NSCLC (NCT02460367). Ongoing basket trials in solid malignancies including NSCLC are testing other IDO inhibitors alone or in combination with checkpoint inhibitors (NCT02048709, NCT02073123).

\section{EMERGING PD1/PDL1 IMMUNOTHERAPY COMBINATIONS WITH CTLA4 INHIBITORS, CHEMOTHERAPY, AND TARGETED THERAPY}

Immunotherapy combinations hold promise to further increase ORR and OS and outperform chemotherapy in NSCLC in the first line settings, based on success of nivolumab/ipilimumab combination in metastatic melanoma, now FDA approved based on CheckMate067 trial results (56).

Multiple studies are evaluating the role of frontline immunotherapy in treatment-naïve NSCLC patients. CheckMate012 trial included 148 treatment-naïve NSCLC patients with PDL-1 expression $>1 \%$; $80 \%$ patients had non-squamous histology. Arm A patients received nivolumab and ipilimumab Q3 weeks with ORR 13\%, arm B - nivolumab $1 \mathrm{mg} / \mathrm{kg}$ Q2 weeks, ipilimumab $1 \mathrm{mg} / \mathrm{kg}$ Q6 weeks, ORR was 25\%. Arm C had the best ORR of 39\% when nivolumab was given $3 \mathrm{mg} /$ kg Q2 weeks and ipilimumab $1 \mathrm{mg} / \mathrm{kg}$ Q12 weeks. Arm D had an ORR 31\% - nivolumab Q2 weeks, ipilimumab Q6 weeks. Median duration of response was not reached (57). A phase II single-arm ipilimumab-nivolumab trial in metastatic NSCLC is underway (CheckMate 568, NCT02659059). Important ongoing phase III studies that might change the treatment landscape of NSCLC are KEYNOTE-024 comparing pembrolizumab to chemotherapy in PD-L1 + NSCLC, and CheckMate 026 with nivolumab, both in treatment-naïve advanced NSCLC patients.

CheckMate 227, a phase III ipilimumab-nivolumab study in treatment-naïve advanced NSCLC in comparison to chemotherapy, is ongoing (NCT02477826). Combination of PD-L1 inhibitor durvalumab and CTLA4 inhibitor tremelimumab was recently studied in a phase Ib study of 102 pretreated NSCLC patients. Significant dose-limiting toxicities were seen in durvalumab $20 \mathrm{mg} / \mathrm{kg}$, tremelimumab $3 \mathrm{mg} / \mathrm{kg}$ cohort. Encouraging ORR of $23 \%$ irrespective of PD-L1 status was observed in patients treated with durvalumab $20 \mathrm{mg} / \mathrm{kg}$ and tremelimumab $1 \mathrm{mg} / \mathrm{kg}$ (24). MYSTIC and NEPTUNE are ongoing phase III studies comparing this combination to platinum-based chemotherapy in treatment-naïve NSCLC patients (NCT02453282, NCT02542293).

Immunotherapy was pioneered in relatively chemoresistant tumors, melanoma, and renal cancer. Historically, platinumdoublet chemotherapy in NSCLC has ORR 30\% with median OS 11-13 months $(26,58,59)$. Addition of bevacizumab had modest effect on OS (60). Immunotherapy success in NSCLC opened possibilities of combining PD1/PDL1 inhibitors with platinumbased doublet chemotherapies in a relatively chemosensitive tumor. KEYNOTE-021 is one such trial (61). Treatment-naïve stage IIIB/IV NSCLC patients were randomized to pembrolizumab in combination with carboplatin/paclitaxel (cohort A), carboplatin/paclitaxel/bevacizumab (cohort B), and carboplatin/ pemetrexed (cohort C). ORR in cohort $\mathrm{C}$ was $71 \%$ compared with cohort A (52\%). Similar ORR was seen in patients expressing $<1 \% \mathrm{PD}-\mathrm{L} 1$. The carboplatin/pemetrexed/pembrolizumab combination is now tested in a larger study (NCT02039674). Another phase III trial KENOTE-189 is comparing platinumdoublet \pm pembrolizumab in advanced NSCLC patients (NCT02578680).

In EGFR or ALK-positive NSCLC, several early phase trials are ongoing, combining PD-1 and CTLA-4 checkpoint inhibitors with EGFR (erlotinib, afatinib, osimertinib) or ALK (crizotinib) tyrosine kinase inhibitors (TKIs) in treatment-naive and previously treated patients (NCT01998126, NCT02511184). TATTON is a multi-arm phase $\mathrm{Ib}$ trial of durvalumab with osimertinib. Dose escalation arm included EGFR TKI-naïve patients, while the expansion cohort included patients progressing on prior TKIs. Although the combination showed clinical activity, 38\% rate of interstitial lung disease was reported with the combination, disproportionate to what is expected with each agent alone. The combination arm has been put on hold (62). A phase I feasibility trial of afatinib and pembrolizumb for patients with EGFR mutation-positive NSCLC progressing on erlotinib is recruiting (NCT02364609). 
TABLE 1 | Selected immunotherapy studies in metastatic NSCLC.

\begin{tabular}{|c|c|c|c|c|}
\hline Experimental arm & Comparator arm & Patient population & $\begin{array}{l}\text { Trial } \\
\text { stage }\end{array}$ & $\begin{array}{l}\text { Primary end point (trial identification } \\
\text { number) }\end{array}$ \\
\hline $\begin{array}{l}\text { Nivolumab vs. nivolumab + ipilimumab } \\
\text { vs. nivolumab + platinum-doublet } \\
\text { chemotherapy (CHECKMATE 227) }\end{array}$ & $\begin{array}{l}\text { Platinum-doublet } \\
\text { chemotherapy }\end{array}$ & Treatment naïve stage IV NSCLC & III & $\begin{array}{l}\text { Overall survival progression-free survival } \\
\text { (NCT02477826) }\end{array}$ \\
\hline $\begin{array}{l}\text { Nivolumab + ipilimumab } \\
\text { (CHECKMATE 568) }\end{array}$ & None-single arm & Treatment naïve stage IV NSCLC & $\|$ & $\begin{array}{l}\text { Overall response rate (ORR) } \\
\text { (NCT02659059) }\end{array}$ \\
\hline $\begin{array}{l}\text { Nivolumab or ipilimumab + erlotinib } \\
\text { (EGFR mutant) or crizotinib } \\
\text { (ALK mutant) }\end{array}$ & None-single arm & $\begin{array}{l}\text { Stage IV NSCLC failed prior } \\
\text { platinum-based therapy }\end{array}$ & 1 & $\begin{array}{l}\text { Toxicity of nivolumab or ipilimumab in } \\
\text { combination with erlotinib (EGFR-mutant } \\
\text { NSCLC) or crizotinib (ALK mutant NSCLC) }\end{array}$ \\
\hline $\begin{array}{l}\text { Nivolumab + ALT } 803 \text { (novel recombinant } \\
\text { IL-15 complex) }\end{array}$ & None & $\begin{array}{l}\text { Stage IIIb/IV NSCLC failed prior } \\
\text { platinum-based therapy }\end{array}$ & $\mathrm{lb} / \mathrm{ll}$ & $\begin{array}{l}\text { Phase Ib - dose-limiting toxicity of ALT } \\
803 \text { nivolumab combination } \\
\text { Phase II - ORR (NCT02523469) }\end{array}$ \\
\hline Pembrolizumab + vorinostat & None & $\begin{array}{l}\text { Stage IV NSCLC progressed on } \\
\text { at least one prior therapy }\end{array}$ & $\mathrm{lb} / \mathrm{II}$ & $\begin{array}{l}\text { Phase Ib - maximum tolerated dose } \\
\text { Phase II - ORR (NCT02638090) }\end{array}$ \\
\hline Pembrolizumab (KEYNOTE-024) & Doublet chemotherapy & $\begin{array}{l}\text { Treatment naïve stage IV NSCLC } \\
\text { with strongly expressing PD-L1 }\end{array}$ & III & PFS (NCT024142738) \\
\hline $\begin{array}{l}\text { Multi-arm pembrolizumab plus } \\
\text { chemotherapy or immunotherapy } \\
\text { (KEYNOTE-021) }\end{array}$ & None & Treatment naïve stage IV NSCLC & $\mid / I I$ & $\begin{array}{l}\text { Part I - recommended phase II dose of } \\
\text { pembrolizumab } \\
\text { Part II - ORR (NCT02039674) }\end{array}$ \\
\hline $\begin{array}{l}\text { Durvalumab vs. durvalumab plus } \\
\text { tremelimumab (MYSTIC) }\end{array}$ & $\begin{array}{l}\text { Standard of care platinum- } \\
\text { doublet chemotherapy }\end{array}$ & Treatment naïve stage IV NSCLC & III & OS and PFS (NCT02453282) \\
\hline $\begin{array}{l}\text { Durvalumab plus tremelimumab } \\
\text { (NEPTUNE) }\end{array}$ & $\begin{array}{l}\text { Standard of care platinum- } \\
\text { doublet chemotherapy }\end{array}$ & Treatment naïve stage IV NSCLC & III & OS (NCT02542293) \\
\hline $\begin{array}{l}\text { Atezolizumab + carboplatin/ } \\
\text { paclitaxel } \pm \text { bevacizumab }\end{array}$ & $\begin{array}{l}\text { Caboplatin }+ \text { paclitaxel }+ \\
\text { bevacizumab }\end{array}$ & $\begin{array}{l}\text { Treatment naïve NSCLC - } \\
\text { non-squamous histology }\end{array}$ & III & PFS (NCT02366143) \\
\hline Atezolizumab & $\begin{array}{l}\text { Gemcitabine + ciplatin or } \\
\text { carboplatin }\end{array}$ & $\begin{array}{l}\text { Treatment naïve NSCLC - } \\
\text { squamous histology }\end{array}$ & III & PFS (NCT02367794) \\
\hline $\begin{array}{l}\text { MGB453 (anti TIM-3) plus PDR001 } \\
\text { (anti PD-1) }\end{array}$ & None & $\begin{array}{l}\text { Multiple advanced solid } \\
\text { malignancies including NSCLC } \\
\text { progressed on standard therapy }\end{array}$ & $|-| \mathrm{b} / \mathrm{II}$ & $\begin{array}{l}\text { Safety and tolerability of MGB453 } \\
\text { in combination with PDR001 } \\
\text { ORR (NCT02608268) }\end{array}$ \\
\hline $\begin{array}{l}\text { LAG525 (anti LAG-3) single agent and in } \\
\text { combination with PDR001 (anti PD-1) }\end{array}$ & None & $\begin{array}{l}\text { Multiple advanced solid } \\
\text { malignancies including NSCLC } \\
\text { progressed on standard therapy }\end{array}$ & $\mid / I I$ & $\begin{array}{l}\text { Phase I-dose-limiting toxicity } \\
\text { Phase II-ORR }\end{array}$ \\
\hline
\end{tabular}

\section{Immune-Mediated Toxicity}

Immunotherapy is associated with increased frequency of immune-related side effects, a spectrum of side effects that are broadly termed immune-related adverse events (irAEs) (63). irAEs with PD-1/PD-L1 inhibitors are less common (7-13\%) compared to toxicities with CTLA4 inhibitors (10-18\%) (15-17, $63,64)$.

The most frequent side effect with PD-1/PD-L1 inhibitors is fatigue, reported among $14-32 \%$ patients in phase III studies $(17-19,23)$. Organ-specific common side effects include skin toxicities such as rash (9\%), diarrhea/colitis (7-8\%), hypothyroidism (7-8\%), hepatitis (1-3\%), adrenal insufficiency (1\%), and thyroiditis (1\%) (17-19). Grade 3/4 pneumonitis has been reported in NSCLC (3\%) with rare treatment-related deaths from pneumonitis $(64,65)$.

Frequency of irAE from combination immunotherapies is higher. In phase Ib study of treatment-naïve NSCLC patients receiving durvalumab and tremelimumab, serious adverse events were reported in $36 \%$ patients. The most frequent grade $3 / 4$ toxicities were diarrhea (11\%), colitis (9\%), and increased lipase (8\%) with three treatment-related deaths (24). Toxicity analysis from multi-cohort CheckMate 012 showed 29-35\% grade $3 / 4$ toxicity in nivoluamb plus ipilimumab combination arms compared to $19 \%$ grade $3 / 4$ toxicity in the nivolumab-only $\operatorname{arm}(57,66)$.

\section{CONCLUSION}

Advances in immunotherapy in metastatic NSCLC now include nivolumab and pembrolizumab that are standard in second line settings, where both agents significantly improve survival. The treatment paradigm changed with introduction of immunotherapy and is expected to start impacting first-line treatment approaches soon. Ongoing challenges include understanding mechanisms of resistance to immunotherapy drugs, development of biomarkers, and predictive scores for better patient selection. Table 1 summarizes ongoing immunotherapy trials in advanced NSCLC, and Figure 1 describes mechanisms of action of select agents. New immunotherapy drugs and novel immunotherapy combinations in frontline and recurrent settings in NSCLC 


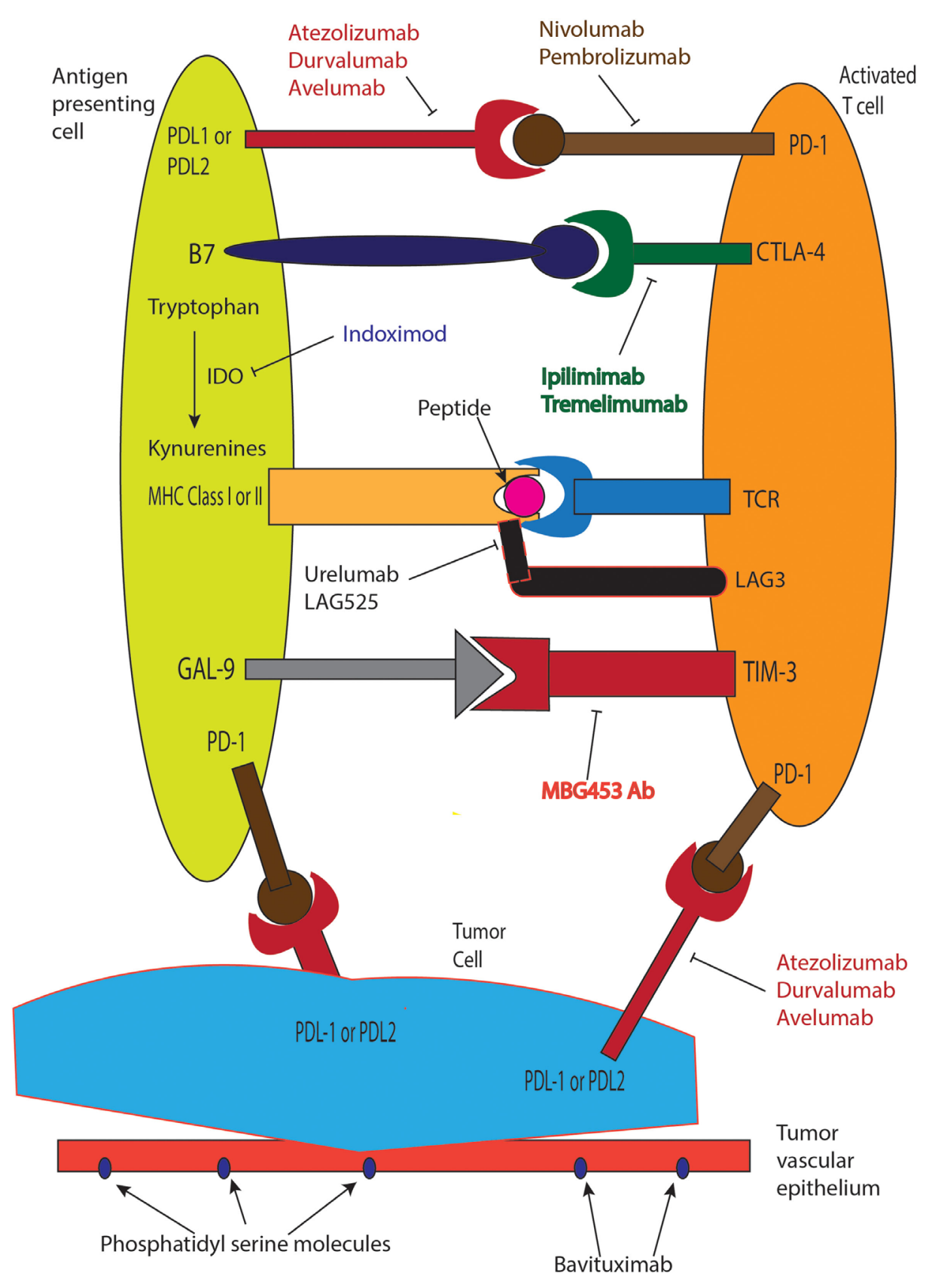

FIGURE 1 | Mechanism of action of clinically used immunotherapeutic agents.

remains one of the most exciting and rapidly evolving areas in oncology, with hope to increase the numbers of long-term survivors with stage IV lung cancer in the near future.

\section{AUTHOR CONTRIBUTIONS}

First author - $\mathrm{PB}$ - prepared manuscript and table. Corresponding author - YB - prepared part of the manuscript and table and provided guidance to the first author in preparing the manuscript; also helped in editing the article and the figure. Co-author - DO prepared the figure. Co-author - GS - helped with review and vital modifications along with suggestions to improve the content. Co-author - GG - helped with review and edition along with suggestions to improve the content.

\section{FUNDING}

The study was supported by NCI P30 CA118100 Core Grant Funding to UNM Comprehensive Cancer Center (PB, DO, GG, and YB), NCI P30 Core Grant CA016672 to MD Anderson Cancer Center (GS), and DOD career development award LC140074 (YB). 


\section{REFERENCES}

1. Burnet M. Cancer: a biological approach. III. Viruses associated with neoplastic conditions. IV. Practical applications. Br Med J (1957) 1(5023):841-7. doi:10.1136/bmj.1.5023.841

2. Zhuang X, Zhang X, Xia X, Zhang C, Liang X, Gao L, et al. Ectopic expression of TIM-3 in lung cancers: a potential independent prognostic factor for patients with NSCLC. Am J Clin Pathol (2012) 137(6):978-85. doi:10.1309/ AJCP9Q6OVLVSHTMY

3. Zippelius A, Batard P, Rubio-Godoy V, Bioley G, Liénard D, Lejeune F, et al. Effector function of human tumor-specific CD8 T cells in melanoma lesions: a state of local functional tolerance. Cancer Res (2004) 64(8):2865-73. doi:10.1158/0008-5472.CAN-03-3066

4. Zajac AJ, Blattman JN, Murali-Krishna K, Sourdive DJ, Suresh M, Altman JD, et al. Viral immune evasion due to persistence of activated T cells without effector function. J Exp Med (1998) 188(12):2205-13. doi:10.1084/jem.188.12.2205

5. Wherry EJ, Ha SJ, Kaech SM, Haining WN, Sarkar S, Kalia V, et al. Molecular signature of CD8+ T cell exhaustion during chronic viral infection. Immunity (2007) 27(4):670-84. doi:10.1016/j.immuni.2007.09.006

6. Wherry EJ, Kurachi M. Molecular and cellular insights into T cell exhaustion. Nat Rev Immunol (2015) 15(8):486-99. doi:10.1038/nri3862

7. Atkins MB, Lotze MT, Dutcher JP, Fisher RI, Weiss G, Margolin K, et al. High-dose recombinant interleukin 2 therapy for patients with metastatic melanoma: analysis of 270 patients treated between 1985 and 1993. J Clin Oncol (1999) 17(7):2105-16.

8. Atkins MB, Kunkel L, Sznol M, Rosenberg SA. High-dose recombinant interleukin-2 therapy in patients with metastatic melanoma: long-term survival update. Cancer J Sci Am (2000) 6(Suppl 1):S11-4.

9. Wolchok JD, Kluger H, Callahan MK, Postow MA, Rizvi NA, Lesokhin AM, et al. Nivolumab plus ipilimumab in advanced melanoma. N Engl J Med (2013) 369(2):122-33. doi:10.1056/NEJMoa1302369

10. Postow MA, Chesney J, Pavlick AC, Robert C, Grossmann K, McDermott D, et al. Nivolumab and ipilimumab versus ipilimumab in untreated melanoma. N Engl J Med (2015) 372(21):2006-17. doi:10.1056/NEJMoa1414428

11. Einhorn LH, Bond WH, Hornback N, Joe BT. Long-term results in combined-modality treatment of small cell carcinoma of the lung. Semin Oncol (1978) 5(3):309-13.

12. Jansen RL, Slingerland R, Goey SH, Franks CR, Bolhuis RL, Stoter G. Interleukin-2 and interferon-alpha in the treatment of patients with advanced non-small-cell lung cancer. JImmunother (1992) 12(1):70-3. doi:10.1097/00002371-199207000-00009

13. Topalian SL, Hodi FS, Brahmer JR, Gettinger SN, Smith DC, McDermott DF, et al. Safety, activity, and immune correlates of anti-PD-1 antibody in cancer. N Engl J Med (2012) 366(26):2443-54. doi:10.1056/NEJMoa1200690

14. Gettinger SN, Horn L, Gandhi L, Spigel DR, Antonia SJ, Rizvi NA, et al. Overall survival and long-term safety of nivolumab (anti-programmed death 1 antibody, BMS-936558, ONO-4538) in patients with previously treated advanced non-small-cell lung cancer. J Clin Oncol (2015) 33(18):2004-12. doi:10.1200/JCO.2014.58.3708

15. Brahmer J, Reckamp KL, Baas P, Crinò L, Eberhardt WEE, Poddubskaya E, et al. Nivolumab versus docetaxel in advanced squamous-cell non-smallcell lung cancer. N Engl JMedicine (2015) 373(2):123-35. doi:10.1056/ NEJMoa1504627

16. Borghaei H, Paz-Ares L, Horn L, Spigel DR, Steins M, Ready NE, et al. Nivolumab versus docetaxel in advanced nonsquamous non-small-cell lung cancer. N Engl J Med (2015) 373(17):1627-39. doi:10.1056/NEJMoa1507643

17. Herbst RS, Baas P, Kim DW, Felip E, Pérez-Gracia JL, Han JY, et al. Pembrolizumab versus docetaxel for previously treated, PD-L1-positive, advanced non-small-cell lung cancer (KEYNOTE-010): a randomised controlled trial. Lancet (2016) 387(10027):1540-50. doi:10.1016/S0140-6736(15)01281-7

18. Dong H, Zhu G, Tamada K, Chen L. B7-H1, a third member of the B7 family, co-stimulates T-cell proliferation and interleukin-10 secretion. Nat Med (1999) 5(12):1365-9. doi:10.1038/70932

19. Latchman Y, Wood CR, Chernova T, Chaudhary D, Borde M, Chernova I, et al. PD-L2 is a second ligand for PD-1 and inhibits T cell activation. Nat Immunol (2001) 2(3):261-8. doi:10.1038/85330

20. Freeman GJ, Long AJ, Iwai Y, Bourque K, Chernova T, Nishimura H, et al. Engagement of the PD-1 immunoinhibitory receptor by a novel B7 family member leads to negative regulation of lymphocyte activation. JExp Med (2000) 192(7):1027-34. doi:10.1084/jem.192.7.1027
21. Fehrenbacher L, Spira A, Ballinger M, Kowanetz M, Vansteenkiste J, Mazieres J, et al. Atezolizumab versus docetaxel for patients with previously treated non-small-cell lung cancer (POPLAR): a multicentre, open-label, phase 2 randomised controlled trial. Lancet (2016) 387(10030):1837-46. doi:10.1016/ S0140-6736(16)00587-0

22. Besse B, Johnson M, Janne PA, Garassino M, Eberhardt WEE, Peter S, et al. 16LBA Phase II, single-arm trial (BIRCH) of atezolizumab as first-line or subsequent therapy for locally advanced or metastatic PD-L1-selected nonsmall cell lung cancer (NSCLC). Eur J Cancer (2015) 51:S717-8. doi:10.1016/ S0959-8049(16)31938-4

23. Rizvi NA. Safety and clinical activity of MEDI4736, an anti-programmed cell death-ligand 1 (PD-L1) antibody, in patients with non-small cell lung cancer (NSCLC). J Clin Oncol (2015) 33(S1):8032.

24. Antonia S. Safety and clinical activity of durvalumab (MEDI4736), an antiPD-L1 antibody, in treatment-naïve patients with advanced non-small-cell lung cancer. J Clin Oncol (2016) 34(15_suppl):9029.

25. Gulley JL, Spigel D, Kelly K, Chandler JC, Rajan A, Hassan R, et al. Avelumab (MSB0010718C), an anti-PD-L1 antibody, in advanced NSCLC patients: a phase $1 \mathrm{~b}$, open-label expansion trial in patients progressing after platinum-based chemotherapy. J Clin Oncol (2015) 33(15_suppl):8034.

26. Scagliotti GV, Parikh P, von Pawel J, Biesma B, Vansteenkiste J, Manegold $\mathrm{C}$, et al. Phase III study comparing cisplatin plus gemcitabine with cisplatin plus pemetrexed in chemotherapy-naive patients with advanced-stage nonsmall-cell lung cancer. J Clin Oncol (2008) 26(21):3543-51. doi:10.1200/ JCO.2007.15.0375

27. Taube JM, Anders RA, Young GD, Xu H, Sharma R, McMiller TL, et al. Colocalization of inflammatory response with B7-h1 expression in human melanocytic lesions supports an adaptive resistance mechanism of immune escape. Sci Transl Med (2012) 4(127):127ra137. doi:10.1126/ scitranslmed.3003689

28. Thommen DS, Schreiner J, Müller P, Herzig P, Roller A, Belousov A, et al. Progression of lung cancer is associated with increased dysfunction of $\mathrm{T}$ cells defined by coexpression of multiple inhibitory receptors. Cancer Immunol Res (2015) 3(12):1344-55. doi:10.1158/2326-6066.CIR-15-0097

29. Rizvi NA, Hellmann MD, Snyder A, Kvistborg P, Makarov V, Havel JJ, et al. Cancer immunology. Mutational landscape determines sensitivity to PD-1 blockade in non-small cell lung cancer. Science (2015) 348(6230):124-8. doi:10.1126/science.aaa1348

30. Blank CU, Haanen JB, Ribas A, Schumacher TN. Cancer immunology. The "cancer immunogram". Science (2016) 352(6286):658-60. doi:10.1126/science. aaf2834

31. Hoos A, Ibrahim R, Korman A, Abdallah K, Berman D, Shahabi V, et al. Development of ipilimumab: contribution to a new paradigm for cancer immunotherapy. Semin Oncol (2010) 37(5):533-46. doi:10.1053/j. seminoncol.2010.09.015

32. Thomas A, Hassan R. Immunotherapies for non-small-cell lung cancer and mesothelioma. Lancet Oncol (2012) 13(7):e301-10. doi:10.1016/ S1470-2045(12)70126-2

33. Lynch TJ, Bondarenko I, Luft A, Serwatowski P, Barlesi F, Chacko R, et al. Ipilimumab in combination with paclitaxel and carboplatin as first-line treatment in stage IIIB/IV non-small-cell lung cancer: results from a randomized, double-blind, multicenter phase II study. J Clin Oncol (2012) 30(17):2046-54. doi:10.1200/JCO.2011.38.4032

34. Timp W, Feinberg AP. Cancer as a dysregulated epigenome allowing cellular growth advantage at the expense of the host. Nat Rev Cancer (2013) 13(7):497-510. doi:10.1038/nrc3486

35. Cowan LA, Talwar S, Yang AS. Will DNA methylation inhibitors work in solid tumors? A review of the clinical experience with azacitidine and decitabine in solid tumors. Epigenomics (2010) 2(1):71-86. doi:10.2217/ epi.09.44

36. Juergens RA, Rudin CM. Aberrant epigenetic regulation: a central contributor to lung carcinogenesis and a new therapeutic target. Am Soc Clin Oncol Educ Book (2013) 2013:295-300. doi:10.1200/EdBook_AM.2013.33.e295

37. Juergens RA, Wrangle J, Vendetti FP, Murphy SC, Zhao M, Coleman B, et al. Combination epigenetic therapy has efficacy in patients with refractory advanced non-small cell lung cancer. Cancer Discov (2011) 1(7):598-607. doi:10.1158/2159-8290.CD-11-0214

38. Roulois D, Loo Yau H, Singhania R, Wang Y, Danesh A, Shen SY, et al. DNA-demethylating agents target colorectal cancer cells by inducing viral 
mimicry by endogenous transcripts. Cell (2015) 162(5):961-73. doi:10.1016/j. cell.2015.07.056

39. Romero D. Immunotherapy: PD-1 says goodbye, TIM-3 says hello. Nat Rev Clin Oncol (2016) 13(4):202-3. doi:10.1038/nrclinonc.2016.40

40. Wrangle J, Wang W, Koch A, Easwaran H, Mohammad HP, Vendetti F, et al. Alterations of immune response of non-small cell lung cancer with azacytidine. Oncotarget (2013) 4(11):2067-79. doi:10.18632/ oncotarget. 1542

41. Koyama S, Akbay EA, Li YY, Herter-Sprie GS, Buczkowski KA, Richards WG, et al. Adaptive resistance to therapeutic PD-1 blockade is associated with upregulation of alternative immune checkpoints. Nat Commun (2016) 7:10501. doi:10.1038/ncomms10501

42. Triebel F, Jitsukawa S, Baixeras E, Roman-Roman S, Genevee C, ViegasPequignot E, et al. LAG-3, a novel lymphocyte activation gene closely related to CD4. J Exp Med (1990) 171(5):1393-405. doi:10.1084/jem.171.5.1393

43. Sierro S, Romero P, Speiser DE. The CD4-like molecule LAG-3, biology and therapeutic applications. Expert Opin Ther Targets (2011) 15(1):91-101. doi:10.1517/14712598.2011.540563

44. Huang CT, Workman CJ, Flies D, Pan X, Marson AL, Zhou G, et al. Role of LAG-3 in regulatory T cells. Immunity (2004) 21(4):503-13. doi:10.1016/j. immuni.2004.08.010

45. Woo SR, Turnis ME, Goldberg MV, Bankoti J, Selby M, Nirschl CJ, et al. Immune inhibitory molecules LAG-3 and PD-1 synergistically regulate T-cell function to promote tumoral immune escape. Cancer Res (2012) 72(4):917-27. doi:10.1158/0008-5472.CAN-11-1620

46. Matsuzaki J, Gnjatic S, Mhawech-Fauceglia P, Beck A, Miller A, Tsuji T, et al. Tumor-infiltrating NY-ESO-1-specific CD8+ T cells are negatively regulated by LAG-3 and PD-1 in human ovarian cancer. Proc Natl Acad Sci U S A (2010) 107(17):7875-80. doi:10.1073/pnas.1003345107

47. Gerber DE, Stopeck AT, Wong L, Rosen LS, Thorpe PE, Shan JS, et al. Phase I safety and pharmacokinetic study of bavituximab, a chimeric phosphatidylserine-targeting monoclonal antibody, in patients with advanced solid tumors. Clin Cancer Res (2011) 17(21):6888-96. doi:10.1158/1078-0432.CCR-11-1074

48. Huang X, Bennett $M$, Thorpe PE. A monoclonal antibody that binds anionic phospholipids on tumor blood vessels enhances the antitumor effect of docetaxel on human breast tumors in mice. Cancer Res (2005) 65(10):4408-16. doi:10.1158/0008-5472.CAN-05-0031

49. Chen X, Doffek K, Sugg SL, Shilyansky J. Phosphatidylserine regulates the maturation of human dendritic cells. JImmunol (2004) 173(5):2985-94. doi:10.4049/jimmunol.173.5.2985

50. Gerber DE, Spigel DR, Giorgadze D, Shtivelband M, Ponomarova OV, Shan JS, et al. Docetaxel combined with bavituximab in previously treated, advanced nonsquamous non-small-cell lung cancer. Clin Lung Cancer (2016) 17(3):169-76. doi:10.1016/j.cllc.2016.02.003

51. Kudo Y, Boyd CA. Human placental indoleamine 2,3-dioxygenase: cellular localization and characterization of an enzyme preventing fetal rejection. Biochim Biophys Acta (2000) 1500(1):119-24. doi:10.1016/S09254439(99)00096-4

52. Yamazaki F, Kuroiwa T, Takikawa O, Kido R. Human indolylamine 2,3-dioxygenase. Its tissue distribution, and characterization of the placental enzyme. Biochem J (1985) 230(3):635-8. doi:10.1042/bj2300635

53. Munn DH, Zhou M, Attwood JT, Bondarev I, Conway SJ, Marshall B, et al. Prevention of allogeneic fetal rejection by tryptophan catabolism. Science (1998) 281(5380):1191-3. doi:10.1126/science.281.5380.1191

54. Swanson KA, Zheng Y, Heidler KM, Mizobuchi T, Wilkes DS. CDllc+ cells modulate pulmonary immune responses by production of indoleamine 2,3-dioxygenase. Am J Respir Cell Mol Biol (2004) 30(3):311-8. doi:10.1165/ rcmb.2003-0268OC
55. Prendergast GC, Smith C, Thomas S, Mandik-Nayak L, Laury-Kleintop L, Metz R, et al. Indoleamine 2,3-dioxygenase pathways of pathogenic inflammation and immune escape in cancer. Cancer Immunol Immunother (2014) 63(7):721-35. doi:10.1007/s00262-014-1549-4

56. Larkin J, Chiarion-Sileni V, Gonzalez R, Grob JJ, Cowey L, Lao CD, et al. Combined nivolumab and ipilimumab or monotherapy in untreated melanoma. N Engl J Med (2015) 373(1):23-34. doi:10.1056/NEJMoa1504030

57. Hellmann MDEA. CheckMate 012: safety and efficacy of first-line (1L) nivolumab (nivo; N) and ipilimumab (ipi; I) in advanced (adv) NSCLC. J Clin Oncol (2016) 34(Suppl):abstr 3001.

58. Schiller JH, Harrington D, Belani CP, Langer C, Sandler A, Krook J, et al. Comparison of four chemotherapy regimens for advanced non-small-cell lung cancer. N Engl J Med (2002) 346(2):92-8. doi:10.1056/NEJMoa011954

59. Grønberg BH, Bremnes RM, Fløtten O, Amundsen T, Brunsvig PF, Hjelde HH, et al. Phase III study by the Norwegian lung cancer study group: pemetrexed plus carboplatin compared with gemcitabine plus carboplatin as first-line chemotherapy in advanced non-small-cell lung cancer. J Clin Oncol (2009) 27(19):3217-24. doi:10.1200/JCO.2008.20.9114

60. Sandler A, Gray R, Perry MC, Brahmer J, Schiller JH, Dowalti A, et al. Paclitaxel-carboplatin alone or with bevacizumab for non-small-cell lung cancer. N Engl J Med (2006) 355(24):2542-50. doi:10.1056/NEJMoa061884

61. Papadimitrakopoulou V, Patnaik A, Borghaei H, Stevenson J, Gandhi L, Gubens MA, et al. Pembrolizumab (pembro; MK-3475) plus platinum doublet chemotherapy (PDC) as front-line therapy for advanced non-small cell lung cancer (NSCLC): KEYNOTE-021 cohorts A and C. J Clin Oncol (2015) 33(Suppl):abstr 8031.

62. Ahn MJ, Yang J, Yu H, Saka H, Ramalingam S, Goto K, et al. 136O: osimertinib combined with durvalumab in EGFR-mutant non-small cell lung cancer: results from the TATTON phase Ib trial. J Thorac Oncol (2016) 11(4):S115. doi:10.1016/S1556-0864(16)30246-5

63. Champiat S, Lambotte O, Barreau E, Belkhir R, Berdelou A, Carbonnel F, et al. Management of immune checkpoint blockade dysimmune toxicities: a collaborative position paper. Ann Oncol (2016) 27(4):559-74. doi:10.1093/ annonc/mdv623

64. Ribas A, Kefford R, Marshall MA, Punt CJ, Haanen JB, Marmol M, et al. Phase III randomized clinical trial comparing tremelimumab with standard-of-care chemotherapy in patients with advanced melanoma. JClin Oncol (2013) 31(5):616-22. doi:10.1200/JCO.2012.44.6112

65. Weber JS, D’Angelo SP, Minor D, Hodi FS, Gutzmer R, Neyns B, et al. Nivolumab versus chemotherapy in patients with advanced melanoma who progressed after anti-CTLA-4 treatment (CheckMate 037): a randomised, controlled, open-label, phase 3 trial. Lancet Oncol (2015) 16(4):375-84. doi:10.1016/S1470-2045(15)70076-8

66. Gettinger S, Rizvi NA, Chow LQ, Borghaei H, Brahmer J, Ready N, et al. Nivolumab monotherapy for first-line treatment of advanced non-small-cell lung cancer. J Clin Oncol (2016) 34(25):2980-7. doi:10.1200/jco.2016.66.9929

Conflict of Interest Statement: The authors declare that the research was conducted in the absence of any commercial or financial relationships that could be construed as a potential conflict of interest.

Copyright $\odot 2016$ Bansal, Osman, Gan, Simon and Boumber. This is an open-access article distributed under the terms of the Creative Commons Attribution License (CC $B Y$ ). The use, distribution or reproduction in other forums is permitted, provided the original author(s) or licensor are credited and that the original publication in this journal is cited, in accordance with accepted academic practice. No use, distribution or reproduction is permitted which does not comply with these terms. 